\title{
Una secuencia para promover la alfabetización geocientífica y educación patrimonial en secundaria
}

\author{
Adriana Paz Otero \\ Departamento de Didácticas Aplicadas, Area de Didáctica de las Ciencias Experimentales. Facultad de \\ Ciencias de la Educación. Universidade de Santiago de Compostela (USC). Santiago de Compostela. \\ España.adriana.paz@rai.usc.es \\ ORCID: bttps:/ / orcid.org/0000-0002-8369-3214

\section{Blanca Puig} \\ Departamento de Didácticas Aplicadas, Área de Didáctica de las Ciencias Experimentales. Facultad de \\ Ciencias de la Educación. Universidade de Santiago de Compostela (USC). Santiago de Compostela. \\ España.blanca.puig@usc.es \\ ORCID: bttps:// orcid.org/0000-0002-2503-7032
}

[Recibido: 20 Agosto 2019. Revisado: 4 Diciembre 2019. Aceptado: 22 Enero 2020]

Resumen: Se presenta una secuencia didáctica para el aula de secundaria sobre geodinámica externa y controversias ambientales y patrimoniales. La propuesta se enmarca dentro de las investigaciones sobre prácticas científicas y cuestiones geocientíficas relacionadas con el patrimonio geológico. El objetivo de la secuencia es promover la educación ambiental y patrimonial mediante la alfabetización geológica y el desempeño de prácticas científicas de modelización y argumentación por el alumnado de secundaria. Se discuten algunos resultados relevantes de la puesta en práctica de la secuencia e implicaciones didácticas para su implementación efectiva.

Palabras clave: Patrimonio geológico; Modelización; Cuestiones socio-científicas; Unidad didáctica; Argumentación.

A sequence to promote geoscientific literacy and heritage education

Abstract: We present a teaching sequence for the secondary school classroom about external geodynamics and environmental and heritage controversies. The proposal is part of the research on scientific practices and geoscientific issues related to geological heritage. The goal of the sequence is to promote environmental and heritage education through geological literacy and modelling and argumentation practices by secondary students. We present the results of the implementation of the sequence for its effective implementation.

Keywords: Geological heritage; Modelling; Socio-scientific issues; Teaching sequence; Argumentation.

Para citar este artículo: Paz Otero A., Puig B. (2020) Una secuencia para promover la alfabetización geocientífica y educación patrimonial en secundaria. Revista Eureka sobre Enseñanza y Divulgación de las Ciencias 17(2), 2202. doi: 10.25267/Rev_Eureka_ensen_divulg_cienc.2020.v17.i2.2202

\section{Introducción}

En la actualidad, existen diferentes problemas socio-ambientales que derivan de la ruptura del ser humano con su entorno. Para que los ciudadanos se pronuncien con criterio, se vuelve esencial lograr la alfabetización científica, que implica, por un lado, comprender los fenómenos naturales que ocurren en el medio ambiente y, por otro, desarrollar actitudes críticas y participativas para tomar decisiones apropiadas al respecto (Pedrinaci 2013). Un ejemplo de esta problemática es la destrucción de nuestro patrimonio natural (Morón-Mongue y Morón-Mongue 2017). El término patrimonio proviene del latín patri (padre) y onium (recibido), que significa «recibido por línea paterna». De manera simple, podría definirse como «un conjunto de elementos a los que se le asigna un valor para conservarlos y transmitirlos a nuestros descendientes» (Carcavilla 2014). Sin embargo, la noción de patrimonio es compleja y también subjetiva, ya que la valoración de los elementos patrimoniales dependerá de cada

\author{
Revista Eureka sobre Enseñanza y Divulgación de las Ciencias \\ Universidad de Cádi\%. APAC-Eureka. ISSN: 1697-011X \\ http:/ / dx.doi.org/10.25267/Rev_Eurek.a_ensen_divulg_cienc.2020.v17.i2.2202 \\ http:/ / reuredc.uca.es
}


persona, de factores influyentes como el sexo, la edad o el conocimiento del individuo, así como de las tendencias culturales de la época (Morón y Wamba 2008). A pesar de su complejidad conceptual, el patrimonio conforma un buen marco educativo, lo que se fundamenta en su carácter holístico e integrador, dadas sus posibles manifestaciones (patrimonio histórico, artístico, etnológico, científico-tecnológico y natural). Esto facilita el desarrollo de competencias multidisciplinarias y el fomento del pensamiento crítico y participación ciudadana en la vida pública. Las tipologías patrimoniales sólo pueden entenderse como diferentes manifestaciones de una concepción patrimonial global. Diversas materias de ciencias, entre ellas la geología, pueden abordarse así bajo este enfoque, promoviendo la alfabetización y la consecución de ciertos principios educativos (AcevedoDíaz et al. 2005). En ese sentido, la educación desde el patrimonio se vuelve un escenario idóneo para introducir cuestiones socio-científicas (CSC) y facilitar el desempeño de prácticas de pensamiento crítico (Marín Cepeda 2013). No obstante, aun considerando su potencial didáctico, el uso de espacios patrimoniales en la enseñanza de las ciencias es relativamente reciente (Carcavilla 2014). De hecho, hay pocas experiencias innovadoras que aproximen la geología al alumnado de secundaria bajo una perspectiva patrimonial y, en menor medida, empleando controversias socio-científicas.

La secuencia que presentamos en este artículo, «Patrimonio y geodinámica externa. El caso de la Playa de las Catedrales» tiene como objetivo contribuir a la investigación en el campo del patrimonio y la educación ambiental desde un enfoque de alfabetización geológica y prácticas científicas. La propuesta didáctica se fundamenta en los diseños sobre temas socio-científicos (Friedrichsen, Sadler, Sadler, Graham y Brown 2016) y utiliza un enfoque que involucra a estudiantes de secundaria en las prácticas de modelización y argumentación para abordar una controversia sobre un espacio geológico, parte de nuestro patrimonio litoral, como la Playa de las Catedrales.

\section{Patrimonio geológico, pensamiento crítico y controversias geocientíficas}

Dependiendo del conjunto de elementos considerados, se distinguirán diversos tipos de patrimonio. Uno de ellos es el patrimonio natural, constituido en parte por el patrimonio geológico. Este último puede utilizarse como herramienta educativa para abordar contenidos relacionados con la geología. Al mismo tiempo, permite introducir los diferentes elementos patrimoniales y sus singularidades. De esta forma, el alumnado es capaz de otorgarles un valor con mayor fundamento y, en definitiva, comprenden la importancia de su conservación a corto, medio y largo plazo (Carcavilla 2014).

Dadas las posibilidades didácticas comentadas, ya es posible enumerar algunas experiencias en la enseñanza basadas en un enfoque patrimonial. La mayoría de los artículos publicados (Calonge, Fermeli, Meléndez, Carvalho y Rodrigues 2013 o Fuertes-Gutiérrez et al. 2014, entre otros) proponen utilizar lugares de interés geológico, denominados LIG, para el aprendizaje de las ciencias de la Tierra. En general, son experiencias bastante comunes y los resultados obtenidos se consideran muy positivos. Esto se debe, ante todo, al potencial que presenta el LIG como recurso para el estudio de ciertos procesos geológicos que ocurren en el planeta, facilitando su comprensión por parte de los estudiantes. Por otro lado, esta aproximación al patrimonio geológico se convierte en un buen contexto para realizar tareas de corte multidisciplinar, como las relacionadas con la gestión ambiental y territorial, fomentando así el desarrollo específico de competencias sociales y cívicas. En todo caso, las salidas de campo guiadas por el profesorado son la herramienta básica de estas propuestas. Apoyados en enfoques más innovadores, surgen otros proyectos como el diseñado por Fuertes-Gutiérrez y Fernández-Martínez (2014), donde se presenta una actividad dirigida a elaborar nuevos 
listados de LIG que incluyen espacios ubicados en el entorno de los centros educativos. Las autoras concluyen que, bajo esta perspectiva, se pueden enseñar conceptos geológicos y abordar aspectos relacionados con el patrimonio, a la par que se favorece el aprendizaje del alumnado sobre su territorio, lo que crea vínculos positivos y promueve su participación en la conservación del lugar.

El pensamiento simple y el analfabetismo geológico tienden a derivar en una cultura ambiental irresponsable. Por lo tanto, alcanzar una competencia geocientífica y desarrollar un pensamiento crítico son pasos necesarios para que los individuos muestren una capacidad de argumentación y de decisión fundamentada, mejorando así su actitud ambiental en la sociedad (Lacreu 2007). En ese sentido, la educación secundaria tendrá como principal desafío promover que la ciudadanía razone críticamente (Jiménez-Aleixandre 2010).

Existen distintas formas de definir el pensamiento crítico. Jiménez-Aleixandre (2010) propone que el pensamiento crítico es «la capacidad de desarrollar opiniones independientes, adquiriendo el poder de reflexionar y participar en la sociedad». Este pensamiento, de acuerdo a esta autora, incluye una serie de componentes relacionados con la argumentación, como es cuestionar afirmaciones o realizar la búsqueda y el uso de pruebas, y componentes de emancipación, como analizar críticamente discursos legítimos o demostrar opiniones independientes. Abordar en la educación CTS (Ciencia, Tecnología y Sociedad) temas sociales controvertidos relacionados con la ciencia (también conocidos como cuestiones sociocientíficas o por sus abreviaturas de CSC) puede favorecer el desarrollo de un pensamiento crítico. De acuerdo a Sadler (2011), las CSC son complejas y abiertas, formadas por problemas sin soluciones directas que se basan en principios, teorías y datos científicos y, a su vez, están influenciadas por diferentes factores sociales. Considerando lo anterior y de acuerdo con varios autores (por ejemplo, Zeidler, Berkowitz y Bennett 2013), las CSC suponen un buen recurso pedagógico para enseñar ciencia, promover la alfabetización científica y preparar a la ciudadanía para enfrentarse, negociar y decidir sobre situaciones de índole político, económico, ambiental y propias de la vida diaria. A pesar de su importancia, estas cuestiones apenas se abordan en muchas de nuestras aulas. Así, se anteponen las prácticas reproductivas, donde prevalece el contenido científico, a cualquier práctica donde el contexto juegue un papel relevante (Sadler 2011).

Muchos de los estudios sobre CSC trabajan controversias dentro del ámbito de la biología. Por ejemplo, las células madre (Molinatti, Girault y Hammond 2010) o el desarrollo sostenible (Simonneaux y Simonneaux 2009). A mayores, cabe destacar alguna controversia relacionada con las ciencias geológicas. Un ejemplo son los trabajos sobre problemáticas relacionadas con la sismicidad, como la experiencia de Puig, Pérez Maceira y Montero Vilar (2015), sobre la sucesión de seísmos en el Delta del Ebro. Aun así, el número de investigaciones que tratan temas controvertidos en geología es bastante limitado, siendo esta carencia más notable cuando se procuran estudios con un enfoque ambiental o patrimonial.

Tomando como referencia estos aportes, se elabora una unidad didáctica sobre el patrimonio natural y geológico. La propuesta aborda un problema socio-científico relacionado con la conservación y pérdida del patrimonio geológico, con el fin de promover el pensamiento crítico y la educación ambiental y patrimonial entre el alumnado. Partimos de una educación patrimonial basada en el análisis de problemas socialmente relevantes que permita resolver interrogantes que se plantean en la vida diaria relacionados con el entorno natural y elementos patrimoniales que forman parte del paisaje geológico. 
En los siguientes apartados se discute la fundamentación didáctica de la unidad, las actividades de la propuesta y los resultados de su implementación e implicaciones para la práctica futura.

\section{Implementación de la secuencia y toma de datos}

La secuencia didáctica se puso en práctica en un aula de 17 estudiantes (alumnas y alumnos, de edades comprendidas entre los 14 y 15 años, la mayoría de zonas rurales) de $3^{\circ}$ de la ESO, dentro de la materia de Biología y Geología. En esta materia se trabajan contenidos relacionados con el paisaje y la geodinámica externa, necesarios para resolver las actividades diseñadas.

Todas las tareas, excepto la actividad de introducción, se llevaron a cabo en cuatro pequeños grupos mixtos de cuatro o cinco integrantes. La razón de trabajar en grupo es que los estudiantes pudiesen debatir e intercambiar ideas entre ellos, aprendiendo a razonar y argumentar críticamente como medio de justificación y persuasión.

Las actividades de la unidad fueron grabadas en audio y en vídeo para su posterior análisis y transcripción. Los datos recogidos incluyen los informes escritos de las actividades realizadas de manera individual y las representaciones elaboradas en pequeños grupos.

Se examinaron las respuestas escritas a las distintas tareas, en base al análisis del contenido (Bardin 1996). Además, se analizaron las representaciones elaboradas por los grupos sobre el modelado de la Playa de las Catedrales. Para ello, fue necesario elaborar un modelo científico de referencia escolar (anexo 1).

\section{Diseño didáctico y actividades de la secuencia}

El diseño de la secuencia, «Patrimonio y geodinámica externa. El caso de la Playa de las Catedrales», implico la revisión inicial de la literatura relacionada con el tema (Evagorou, Lymbouridou y Nicolaou 2013; Fuertes-Gutiérrez y Fernández-Martínez 2014; Blanco 2015, entre otros) y el análisis detallado de los contenidos científicos abordados sobre los procesos geológicos a trabajar (Vidal y Cotelo 2017).

El diseño fue elaborado por las autoras del artículo, ambas con formación en biología y, una de ellas, investigadora en didáctica de las ciencias experimentales. Parte de las contribuciones innovadoras de esta propuesta se basan en utilizar un contexto patrimonial para introducir contenidos de geología y problemas socio-científicos, mediante el desempeño de prácticas científicas por el alumnado.

Tabla 1. Actividades de la secuencia y objetivos de aprendizaje de cada una de ellas.

\begin{tabular}{|l|l|l|}
\hline Sesiones & Actividades & Objetivos de aprendizaje \\
\hline 1 & $\begin{array}{l}\text { Actividad 1. } \\
\text { ¿ué entiendes tú por } \\
\text { patrimonio? }\end{array}$ & $\begin{array}{l}\text {-Expresar ideas sobre el concepto de patrimonio, la } \\
\text { formación y modelado del paisaje y su conservación. } \\
\text {-Valorar diferentes paisajes según criterios. }\end{array}$ \\
\hline $2-3$ & $\begin{array}{l}\text { Actividad 2. } \\
\text { démo se forma la Playa }\end{array}$ & $\begin{array}{l}\text {-Representar el proceso de formación y modelado de } \\
\text { un paisaje costero gallego. } \\
\text {-Explicar los fenómenos geológicos en base a la } \\
\text { representación elaborada y relacionarlos con los } \\
\text { mecanismos de formación y modelado del paisaje } \\
\text { costero. }\end{array}$ \\
\hline
\end{tabular}


Tabla 1. Continuación

\begin{tabular}{|l|l|l|}
\hline Sesiones & Actividades & Objetivos de aprendizaje \\
\hline 4 & $\begin{array}{l}\text { Actividad 3 (parte 1-2). } \\
\text { ¿Está la Playa de las } \\
\text { Catedrales en peligro? }\end{array}$ & $\begin{array}{l}\text {-Analizar e interpretar información de diferentes } \\
\text { fuentes sobre la controversia relacionada con la Playa } \\
\text { de las Catedrales. } \\
\text {-Diferenciar datos de pruebas científicas en la } \\
\text { información proporcionada. } \\
\text {-Justificar la fiabilidad de la información y distinguir si } \\
\text { tiene una base científica o no. }\end{array}$ \\
\hline 5 & $\begin{array}{l}\text { Actividad 3 (parte 3). } \\
\text { ¿Está la Playa de las } \\
\text { Catedrales en peligro? }\end{array}$ & $\begin{array}{l}\text {-Resolver un problema auténtico utilizando las } \\
\text { representaciones elaboradas. } \\
\text {-Analizar e interpretar información de diferentes } \\
\text { fuentes. } \\
\text {-Relacionar las representaciones con los datos } \\
\text { proporcionados. } \\
\text {-Tomar decisiones para resolver un problema } \\
\text { geológico y patrimonial. }\end{array}$ \\
\hline
\end{tabular}

La unidad consta de tres actividades desarrolladas en cinco sesiones. La tabla 1 resume las tareas, indicando los objetivos de aprendizaje de las mismas. La primera tarea es de introducción y la segunda y tercera son de aplicación de conocimientos y desarrollo de prácticas científicas. La unidad busca promover una educación patrimonial y ambiental. Es decir, que los estudiantes sean críticos y responsables con los elementos naturales y geológicos del patrimonio, y valoren la importancia de estos.

En las siguientes secciones se explican las tareas de la secuencia.

\section{Actividad 1. «¿Qué entiendes tú por patrimonio?»}

Esta actividad es la primera de la secuencia y se desarrolla en una sesión previa a la explicación de los contenidos teóricos. Se desarrolla en tres partes que se resuelven de manera individual. Al finalizar, se hace una puesta en común; de este modo, se contraponen las percepciones propias con las ideas y conocimientos aportados por el resto de compañeros.

\section{Parte 1. Investigando sobre el patrimonio gallego}

Se muestra el siguiente fragmento de una noticia sobre el patrimonio gallego (figura 1):

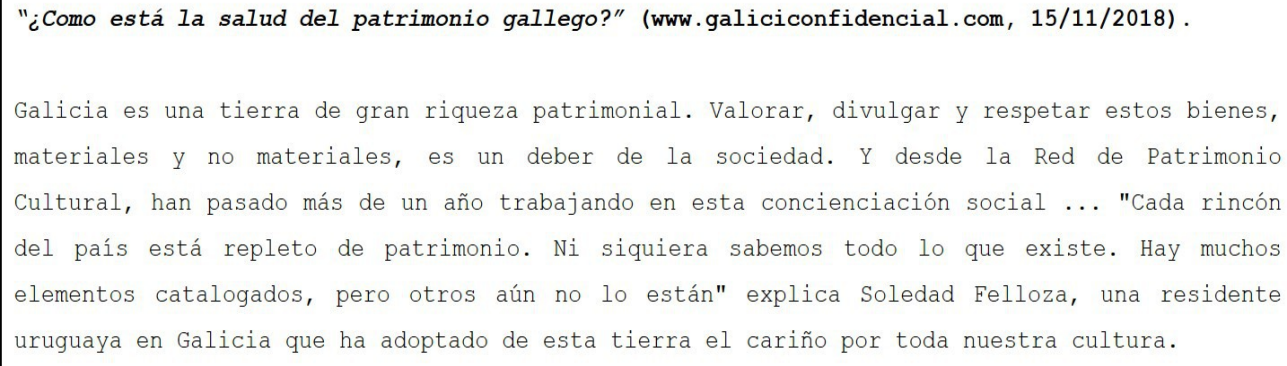

Figura 1. Fragmento de noticia proporcionado en la actividad 1 (parte 1). Recuperado de: http://www.galiciaconfidencial.com/noticia/80234-saude-patrimonio-galego. 
Tras leer la noticia, se pide al alumnado que explique el significado del término patrimonio. A mayores, deben redactar un listado con ejemplos del patrimonio gallego, justificando el porqué de cada elección.

\section{Parte 2. ¿Cómo valorarías estos paisajes?}

La tarea se estructura en dos bloques que se discuten a continuación. En primer lugar, se presentan las imágenes de la figura 2.

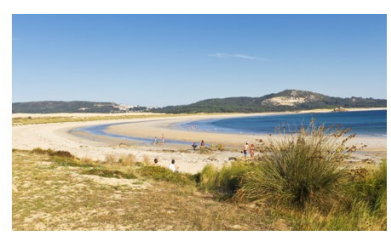

a) Ría de Muros y Noya

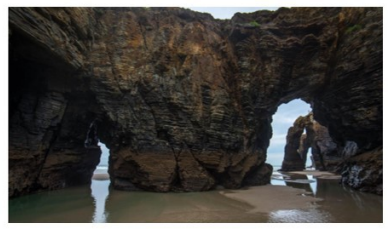

d) Playa de las Catedrales (Ribadeo)

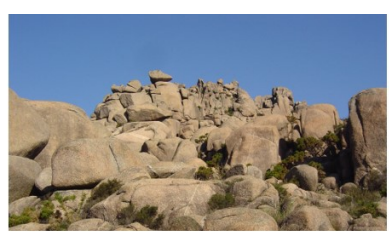

b) El Monte Pindo (Carnota)

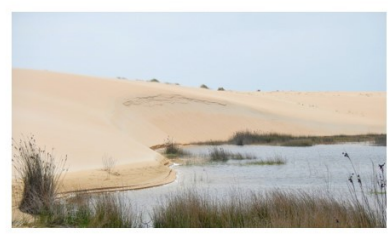

e) Dunas de Corrubedo (Ribeira)

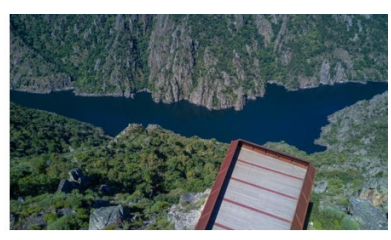

c) Cañones del Sil (Ourense)

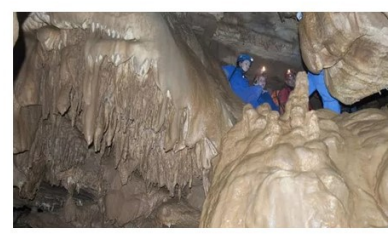

f) La Cueva de Arcoia (EI Courel)

Figura 2. Imágenes de paisajes gallegos presentadas en la actividad 1 (parte 2). Fuentes imágenes: https://www.turismo.gal/que-visitar/destacados/as-rias/; https://www.carnota.gal/turismo/natureza/monte- pindo/;

http://galicianaturaleunica.xunta.gal/gl/ribeira-sacra;

http://galicianaturaleunica.xunta.gal/es/praia-catedrais;

https://www.turismo.gal/que-visitar/espazos-naturais/parques-naturais/complexo-dunar-decorrubedo?langId=es_ES;

https://www.lavozdegalicia.es/noticia/lemos/2018/01/09/cueva-arcoia-peligro-visitasincontroladas/0003_201801M9C12991.htm

Los paisajes que se observan no son elegidos al azar por las autoras, sino que se seleccionan por ser espacios con reconocimiento social o bien por localizarse próximos al centro de enseñanza; además, todos forman parte del patrimonio natural y/o geológico gallego.

En segundo lugar, los estudiantes tienen que cubrir la tabla presentada en la figura 3:

a) Indica que valor tiene para ti cada paisaje.

Marca con la letra $X$ segundo consideres: $1 \rightarrow$ Ningún valor; $2 \rightarrow$ Cierto valor; $3 \rightarrow$ Mucho valor.

b) Justifica tu respuesta, ¿por qué le das ese valor?

c) ¿Qué piensas que puede influir en la formación y modelado de cada paisaje?

\begin{tabular}{|l|l|l|l|l|l|}
\hline \multirow{2}{*}{\multicolumn{1}{|c|}{ PAISAJE }} & \multicolumn{2}{c|}{ a) VALOR } & \multicolumn{2}{c|}{ b) JUSTIFICACIÓN } & \multirow{2}{*}{ c) FORMACIÓN PAISAJE } \\
\cline { 2 - 6 } & 1 & 2 & 3 & & \\
\hline Ría de Muros y Noya & & & & & \\
\hline Monte Pindo & & & & & \\
\hline Cañones del Sil & & & & & \\
\hline Playa de las Catedrales & & & & & \\
\hline Dunas de Corrubedo & & & & & \\
\hline Cueva de Arcoia & & & & & \\
\hline
\end{tabular}

Figura 3. Ejemplo de tabla proporcionada en la actividad 1 (parte 2). Elaboración propia. 
De este modo, se requiere que el alumnado valore con criterio los paisajes del entorno, considerando, al mismo tiempo, los procesos y factores que intervienen en su formación y transformación.

\section{Parte 3. ¿Necesitan protección los paisajes?}

Se presentan dos imágenes de un mismo espacio natural protegido, que corresponde a la Sierra del Courel (figura 4).
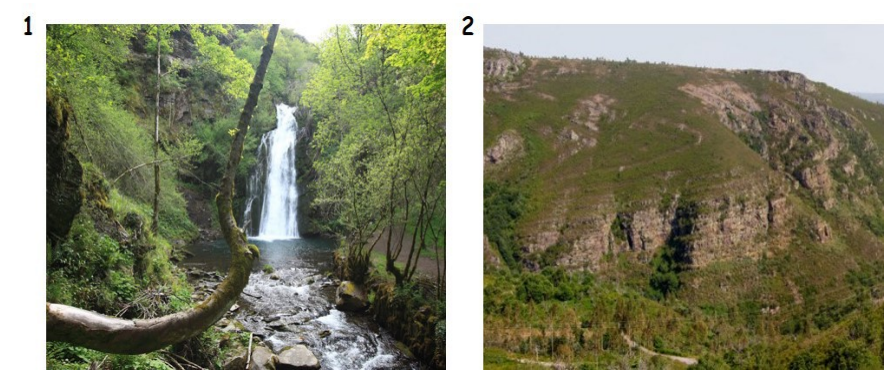

Figura 4. Imágenes de la Sierra del Courel proporcionadas en la actividad 1 (parte 3).

Fuentes imágenes:

https:/ / concellodequiroga.com/wp-content/uploads/2015/11/ fervenza-de-vieiros-02-

1024x683.jpg;

https://concellodequiroga.com/wp-content/uploads/2015/09/SINCLINAL-CAUREL-

4-1024x296.jpg

En la primera imagen se observa una fraga de gran diversidad y en la segunda fotografía se muestra la famosa formación geológica de los Sinclinales del Courel. Sin proporcionar más información, los estudiantes deben considerar si es preciso proteger estos paisajes y, luego, elegir cuál protegerían con mayor prioridad, justificando sus respuestas.

\section{Actividad 2. «¿Cómo se forma la Playa de las Catedrales?»}

Durante la realización de esta actividad, los estudiantes representan en pequeños grupos el proceso de formación y modelado de la Playa de las Catedrales. La tarea abarca dos sesiones y se inicia después de explicar el contenido teórico sobre la acción geológica del mar y las características de los paisajes costeros.

Para contextualizar la tarea, se proporciona la ficha mostrada en la figura 5, elaborada por las autoras, con imágenes e información de la Playa de las Catedrales. A continuación, los estudiantes participan en una ronda oral de preguntas y respuestas durante la cual investigan sobre el estado actual de la playa y respecto su origen o características geológicas. En la segunda sesión, cada grupo comienza a trabajar con la representación del proceso de modelado y formación de la playa.

La docente proporciona las indicaciones mostradas en la figura 6. A mayores, se proporcionan los siguientes materiales (figura 7): una cartulina blanca que sirve de base para la representación; un sobre blanco que contiene las imágenes de las formaciones geológicas y las etapas de modelado de la playa, los nombres de las formaciones geológicas y las descripciones de los procesos geológicos, flechas para relacionar los diferentes elementos y el título de la representación; finalmente, a cada grupo también se le proporciona una barra de pegamento. 


\section{Instrucciones a seguir}

Paso 1. Discutid y planead entre vosotros cómo representaréis el proceso de formación y modelado de la Playa de las Catedrales.

Paso 2. iA trabajar! Representar el proceso en la cartulina y con el material proporcionado.

Paso 3. Revisad vuestro modelo y contestad a las preguntas finales.

Figura 6. Ejemplo de instrucciones proporcionadas en la actividad 2.

Para resolver la actividad propuesta, los estudiantes deben identificar los diferentes elementos proporcionados, ya que ninguno aparece identificado.

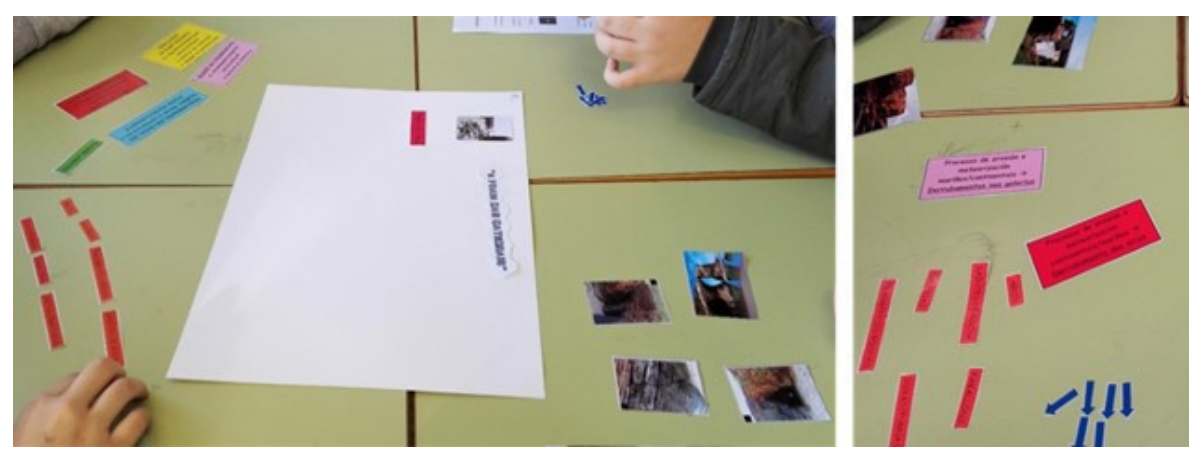

Figura 7. Material empleado para elaborar la representación de la actividad 2. Fuente imágenes: propias de la autora.

A continuación, los miembros de cada grupo deciden por consenso cómo representar el modelo; así, deben ordenar las etapas de formación y modelado en una secuencia temporal lógica y relacionar los procesos geológicos que intervienen en cada etapa. En las imágenes de la figura 8 se puede ver cómo uno de los equipos elabora su representación.
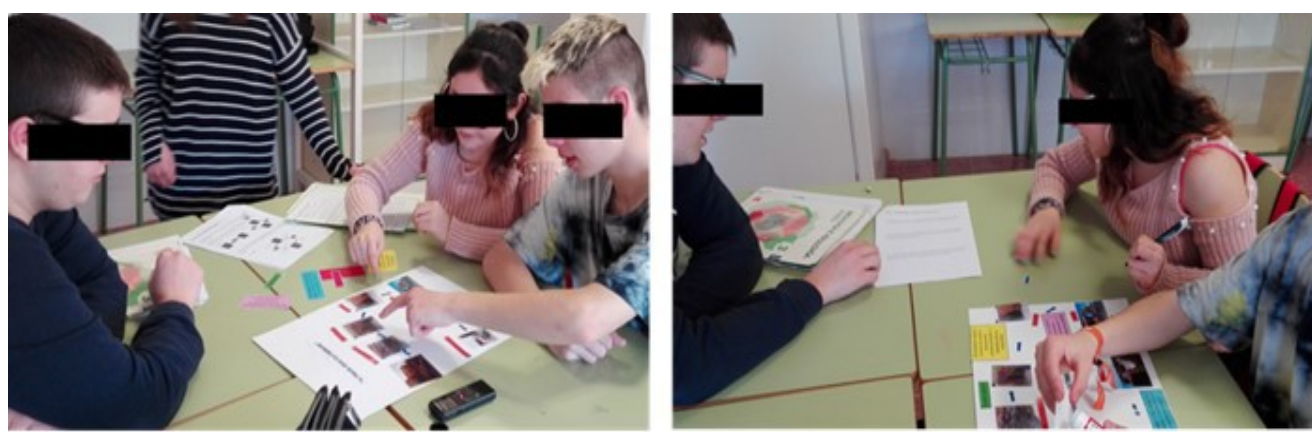

Figura 8. Grupo C representando el proceso de formación y modelado de la Playa de las Catedrales. Fuente imágenes: propias de la autora.

Una vez representado el proceso, se requiere responder a tres cuestiones finales. El objetivo es explicar diferentes fenómenos geológicos y relacionarlos con el mecanismo de formación y modelado del paisaje costero. Específicamente, para abordar esta parte de la tarea, los 
estudiantes deben basarse en su representación, conectándola con el proceso geológico real. Las preguntas propuestas son:

1.1. Viajemos al futuro... Nos encontramos en el año 2119, ¿cambió algo la Playa de las Catedrales? ¿Qué elementos del paisaje cambiaron?

1.2. Si la precipitación se intensifica en Lugo, ¿se verían afectadas de alguna manera las diferentes formaciones de la playa (cuevas, galerías, arcos ...)?

1.3. Las acciones del ser humano parecen contribuir al deterioro de la Playa de las Catedrales. ¿Cómo puede pasar esto?

\section{LA DLAYA DE LAS CATEDIRALES}
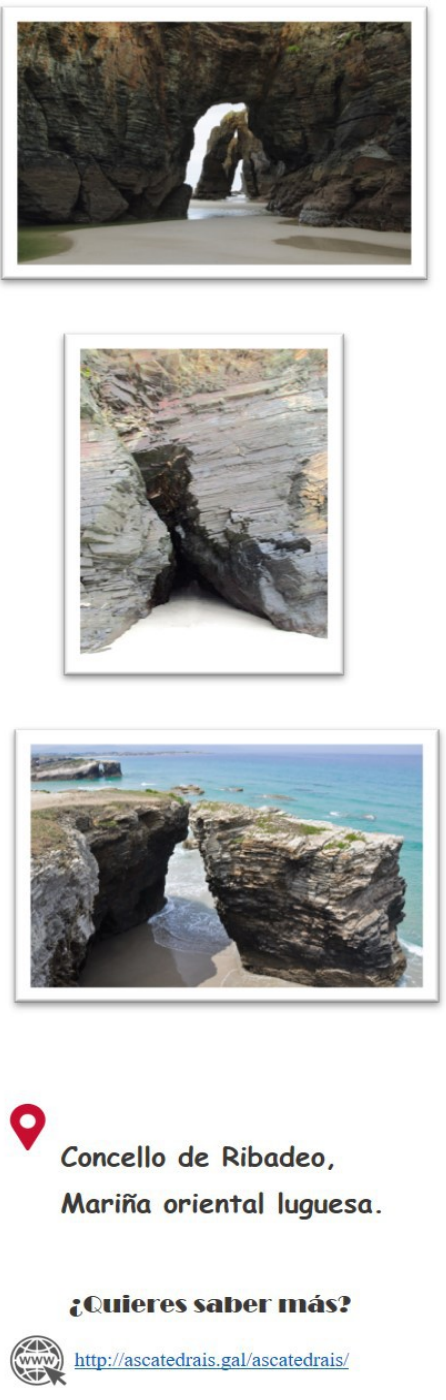

¿Sabias aue....?

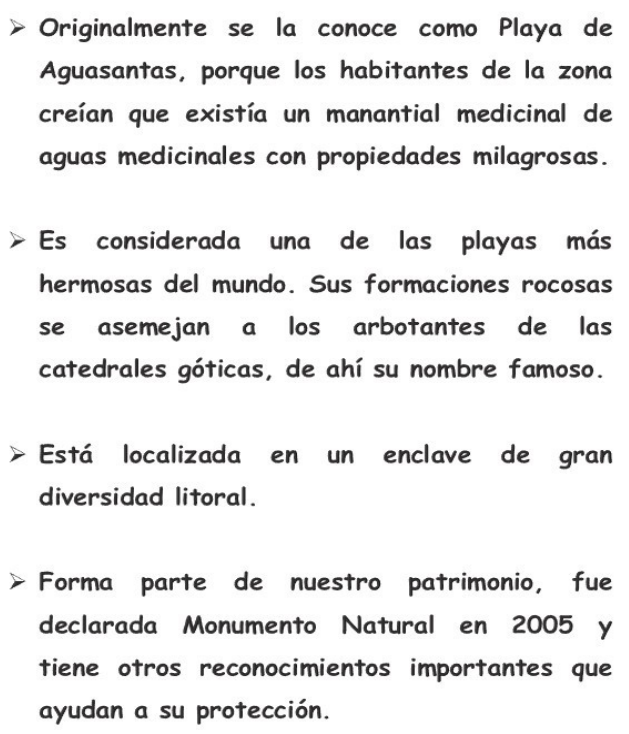
Aguasantas, porque los habitantes de la zona creían que existía un manantial medicinal de aguas medicinales con propiedades milagrosas.

Ds considerada una de las playas más hermosas del mundo. Sus formaciones rocosas se asemejan a los arbotantes de las catedrales góticas, de ahí su nombre famoso.

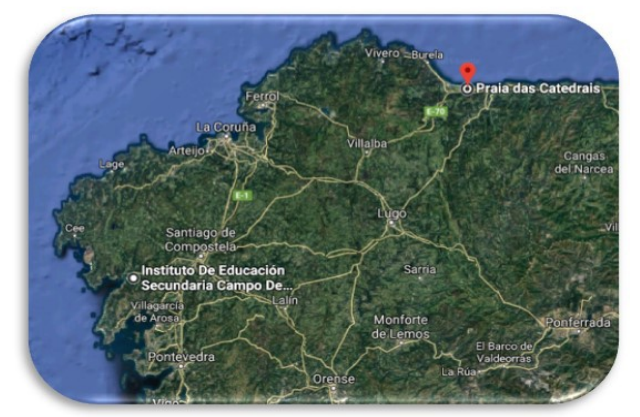

Figura 5. Ejemplo de ficha proporcionada sobre la Playa de las Catedrales en la actividad 2. Fuente imágenes e información: http://ascatedrais.gal/ascatedrais/ 


\section{Actividad 3. «¿Está la Playa de las Catedrales en peligro?»}

Se trata de una actividad de argumentación que requiere, por parte del alumnado, tomar decisiones justificadas y consensuadas acerca de la Playa de las Catedrales. Se presenta la polémica social que afecta a la gestión y conservación de esta playa, un paisaje considerado patrimonio natural y geológico.

La tarea consta de tres partes diferentes y se desarrolla en pequeños grupos a lo largo de dos sesiones. A continuación, se presentan las distintas partes de la actividad.

\section{Parte 1. ¡Catástrofe en la Playa de las Catedrales!}

Se presenta al alumnado el siguiente fragmento de una noticia, relacionada con la gestión de la Playa de las Catedrales (figura 9):

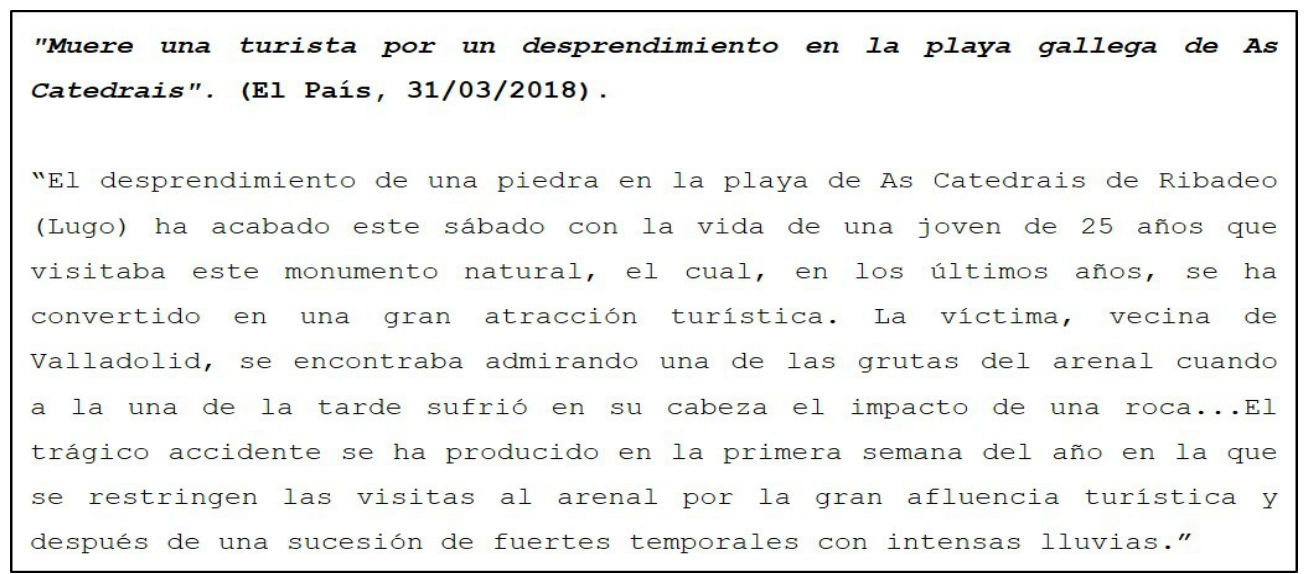

Figura 9. Fragmento de noticia proporcionado en la actividad 3 (parte 1). Recuperado de: https://elpais.com/politica/2018/03/31/actualidad/1522506119_790517.html

Luego, en base a su lectura, los estudiantes tienen que responder estas preguntas:

1.1. ¿Cuáles pueden ser las causas de este desprendimiento en la Playa de las Catedrales?

1.2. ¿Pensáis que se podría haber evitado lo ocurrido de alguna manera? ¿Cómo?

De esta manera, se consigue presentar un contexto de controversia social, invitando al alumnado a reflexionar críticamente sobre el mismo.

\section{Parte 2. Opinando sobre lo sucedido}

Se muestran varias opiniones sobre la controversia anterior (figura 10), extraídas de diferentes periódicos.

A continuación, se expone una serie de cuestiones que los estudiantes deben responder. Esto implica la lectura crítica y el análisis de la información proporcionada. Las preguntas son:

1.1. ¿Con qué opiniones NO estáis de acuerdo? ¿Por qué?

1.2. ¿Todas las afirmaciones muestran la misma fiabilidad? ¿Por qué?

1.3. ¿Todas las declaraciones están respaldadas por pruebas científicas? Indicad cuáles consideráis que sí y cuáles no. 


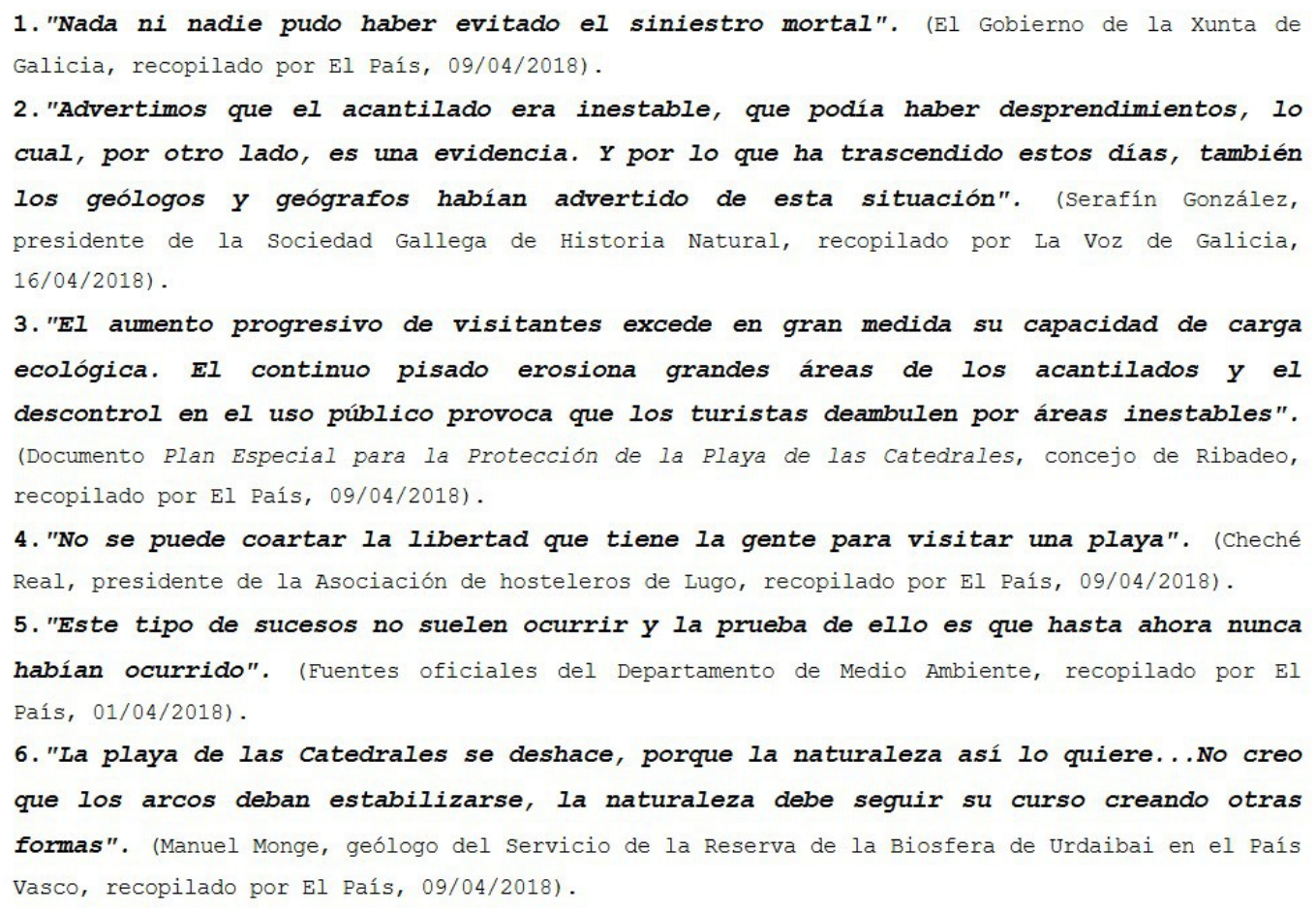

Figura 10. Fragmentos de noticias proporcionados en la actividad 3 (parte 2). Recuperados de: https://elpais.com/politica/2018/04/05/actualidad/1522943084_059654.html;

https://www.lavozdegalicia.es/noticia/galicia/2018/04/16/houbo-unha-promocion-desaforada-das-

catedrais-as-veces-parece-unha-feira/0003_201804G16P9993.htm;

https://elpais.com/politica/2018/04/01/actualidad/1522600907_541807.html

\section{Parte 3. ¿Debemos cuidar la Playa de las Catedrales?}

Finalmente, se propone una tarea para que cada grupo piense en posibles soluciones que permitan gestionar la Playa de las Catedrales. En ese marco, los estudiantes deben seguir varios pasos mostrados en la figura 11.

La medida emprendida por la Xunta de Galicia para limitar el aforo de visitantes en la playa, no parece resolver el problema... Por lo tanto, el gobierno necesita de vuestra ayuda para investigar otras posibles soluciones que permitan, de una vez por todas, proteger el Monumento Natural. Pero, Iojo!, sin que esto afecte a una de las fuentes económicas de la zona, el turismo.

a) Debatid entre los miembros del equipo que medidas tomaríais. Con ellas debéis convencer a tres de los grupos sociales involucrados: 1. Los defensores de la naturaleza; 2. Empresas del sector turístico: 3. Visitantes y turistas.

b) Como verdaderas científicas y científicos, apoyad vuestras decisiones en las pruebas y datos proporcionados. Además, tened en cuenta el proceso de modelado y formación de la playa, representado previamente.

c) Describid vuestras medidas de gestión. Justificadlas. Luego, cada grupo expondrá sus conclusiones al resto de los equipos.

Figura 11. Ejemplo de instrucciones proporcionadas en la actividad 3 (parte 3). 


\section{Nociones del alumnado acerca del patrimonio y uso de criterios en la valoración y protección del paisaje}

El análisis de la actividad 1 indica que parte de los estudiantes tienen en cuenta los elementos naturales cuando expresan ideas sobre la noción de patrimonio. Sin embargo, no se consideran las formaciones geológicas como elementos patrimoniales. Algunas de sus respuestas son:

"Es patrimonio la ría de Noya y Muros" o "Considero patrimonio: ríos, bosques y lagos".

Este resultado apoya la conclusión expuesta por el autor Carcavilla (2014), acerca del desconocimiento generalizado del patrimonio geológico.

Por otro lado, a la hora de valorar el paisaje, son pocos los estudiantes que manejan criterios geocientíficos fundamentados en el origen y características geológicas del lugar. Sus respuestas son como estas:

"Le doy un 3 porque es un paisaje muy hermoso" o "Tiene un 3 porque pertenece al lugar donde vivo".

En cuanto a los criterios que moviliza el alumnado para considerar la protección del paisaje, destaca que la mayoría se basa en la presencia de elementos naturales bióticos, dando prioridad a la protección de paisajes que se caracterizan por su diversidad. Un ejemplo es:

"El bosque debe protegerse con la máxima prioridad. Porque hay un río y abundan los árboles y animales (que tienen vida) y las piedras del segundo paisaje no necesitan protección ".

Esto concuerda con uno de los obstáculos epistemológicos más comunes que conducen a una actitud ambiental negativa. En particular, se trata de la concepción errónea de que el paisaje está constituido únicamente por elementos naturales bióticos (Lacreu 2001). En consecuencia, el alumnado da importancia al paisaje si es un lugar donde abundan especies animales o vegetales. Por lo contrario, otros elementos como las formaciones geológicas pasan desapercibidos y no se consideran de interés o de relevancia para la ciudadanía.

\section{Representaciones y explicaciones elaboradas sobre la formación de la playa}

La representación del proceso geológico permite al alumnado identificar y relacionar con mayor facilidad los elementos involucrados, aproximándose en gran medida al modelo científico escolar de referencia (anexo 1). En la figura 13, se muestra una fotografía de la representación elaborada por el grupo D.

Además, todos los grupos logran conectar la representación con el proceso geológico real, elaborando explicaciones más amplias y justificadas en las cuestiones finales. Por ejemplo, a la pregunta sobre la evolución del estado de la playa, el grupo B contesta: "Los arcos litorales caen totalmente y los farallones se terminan desgastando y caen los sedimentos". A la cuestión sobre las posibles alteraciones en la playa, debido al aumento de precipitaciones, otro grupo, el $\mathrm{D}$, responde: "Aumentaría el proceso de meteorización continental, por lo que las rocas de las formaciones se harían más pequeñas". Por último, a la pregunta sobre el deterioro ocasionado por la acción humana, responden: "Al caminar por encima de las rocas, estas se deformarían y terminarían desgastándose en un largo período de tiempo" (grupo A).

El resultado es similar al descrito en experiencias anteriores, donde se analizó la capacidad de modelización en otros contextos de aprendizaje, demostrando que el desempeño de esta práctica facilita la construcción de explicaciones sobre fenómenos científicos (Agueitos y Puig 2016). 


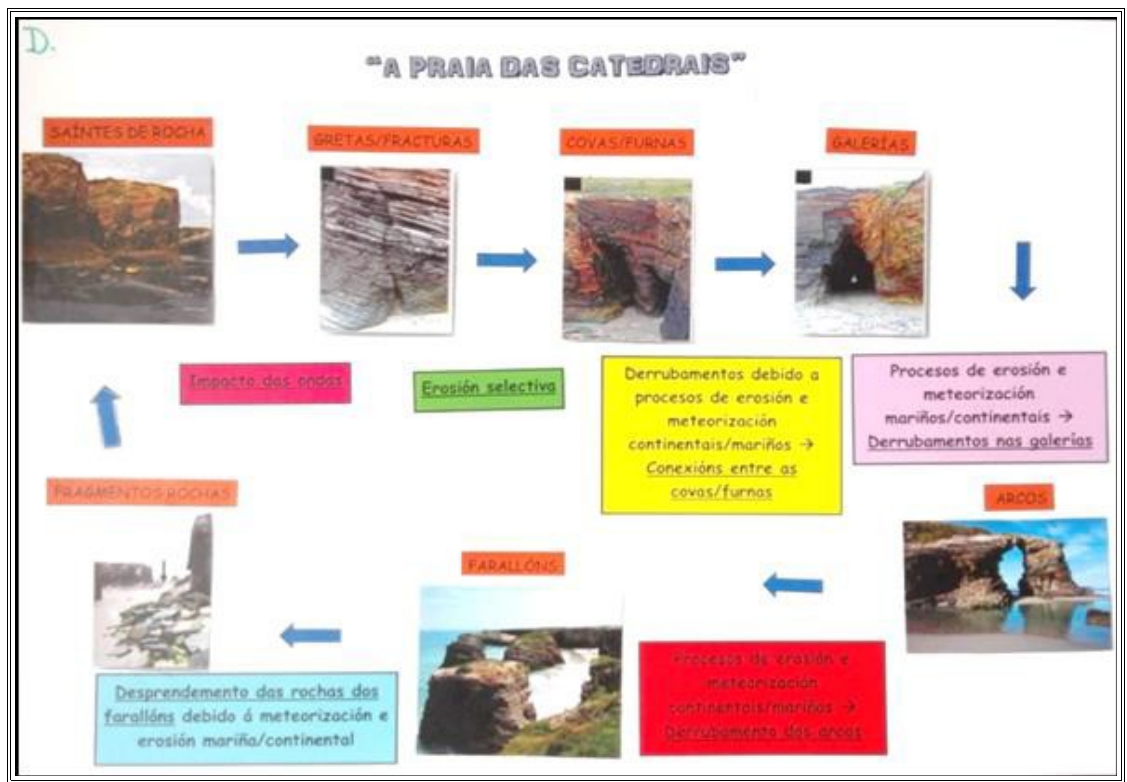

Figura 13. Representación del grupo D en la actividad 2. La representación se elabora en el idioma co-oficial de la comunidad, el gallego.

\section{Uso de pruebas y criterios para gestionar la protección de un paisaje geológico}

Los resultados de la parte 1 de la actividad 3 muestran que los estudiantes se apoyan en el proceso representado para explicar las causas del polémico accidente. Por ejemplo, el grupo C contesta lo siguiente: "Las rocas estaban demasiado erosionadas, por lo que llega un momento en que pueden caer. Esto, además, puede deberse a la sucesión de fuertes temporales que ocasionan mayor erosión". En relación a la segunda cuestión, cómo se podría haber evitado el accidente, uno de los grupos responde: "Que las personas no anden por encima de las rocas, para no deteriorarlas más y causar desprendimientos" (grupo B).

Respecto la parte 2, todos los grupos encuentran diferencias en la fiabilidad de las afirmaciones proporcionadas. Los criterios utilizados para decidir si una opinión es fiable o no, son: a) cómo se justifican esas afirmaciones (por ejemplo, en qué pruebas se respaldan) y b) qué conocimiento posee la persona que expresa la opinión, prestando atención a su especialización académica/profesional. A mayores, todos los grupos son capaces de distinguir qué afirmaciones se sustentan en una base científica y cuáles no.

El análisis de esta actividad muestra algunas discrepancias entre las medidas propuestas para gestionar la Playa de las Catedrales. Uno de los grupos da prioridad a la seguridad física de las personas que visitan la playa, mientras que el resto de estudiantes tienden a priorizar la protección y conservación del paisaje. En todos los casos, los grupos justifican razonadamente sus medidas, relacionando los datos y pruebas proporcionados y apoyándose en la representación previamente elaborada. Algunos ejemplos son:

"Colocar debajo de los arcos, acantilados y galerías, una especie de red que evite el daño causado a las personas por los desprendimientos de rocas debido a la erosión” (grupo A).

"Construir un paseo elevado de madera para proteger la vegetación del acantilado y reducir su deterioro por erosión” (grupo B).

Estos resultados apuntan a que la práctica de modelización parece facilitar la comprensión del contenido teórico, contribuyendo a su vez al desarrollo de argumentos razonados. Estudios previos ya demostraron la relación mutua y beneficiosa que existe entre las prácticas de 
modelización y de argumentación en la enseñanza (McNeill y Krajcik 2008, Evagorou et al. 2013, Blanco 2015).

\section{Implicaciones para la práctica educativa y propuestas de mejora}

Los resultados del trabajo conducen a una reflexión sobre la importancia de introducir contenidos geológicos en la educación secundaria desde una perspectiva patrimonial, promoviendo el desempeño de prácticas científicas, como la modelización o la argumentación crítica.

Cuando se emplea el patrimonio geológico en la enseñanza, es posible transmitir a los estudiantes algunos conocimientos sobre geología y, al mismo tiempo, inculcar el valor del patrimonio y la importancia de preservarlo (Fuertes-Gutiérrez et al., 2014). En otras palabras, hay una conexión mutua entre ambos aspectos. Por un lado, el patrimonio crea un contexto propicio para el aprendizaje de las ciencias geológicas; y por otro, este aprendizaje permite a los estudiantes comprender y conocer los elementos geológicos dese patrimonio, pudiendo construir criterios que justifiquen la necesidad de protegerlo.

En el análisis de la secuencia, el grupo de estudiantes mostró una falta inicial de conocimiento sobre el patrimonio geológico. En particular, se evidenció una falta de criterios geocientíficos para valorar y proteger el paisaje. Estas carencias apoyan la idea de introducir actividades donde se trabaje conjuntamente la geología y los elementos patrimoniales, con el fin de enseñar el interés científico que guardan estos espacios y, en consecuencia, la relevancia que tienen para la sociedad (Carcavilla 2014).

La representación del proceso de formación y modelado de un paisaje costero y patrimonial puede mejorar la competencia geocientífica de los estudiantes y también su actitud ambiental. Primero, da a conocer el patrimonio geológico, algo que, como aboga Carcavilla (2014), es fundamental si buscamos su reconocimiento. Además, el desempeño de la práctica de modelización permite adquirir un mayor entendimiento de contenidos relacionados con la geología. Apoyando esta conclusión, se contempló como los participantes del estudio elaboraron explicaciones más consistentes sobre los fenómenos que afectan al modelado del paisaje apoyándose en sus representaciones. Por lo tanto, este tipo de prácticas parecen afianzar ciertos conocimientos y romper con los obstáculos epistemológicos inherentes al aprendizaje de las ciencias geológicas.

Asimismo, trabajar la secuencia en el marco de una controversia socio-científica, posibilita contextualizar los contenidos, una de las pautas metodológicas esenciales para promover la alfabetización científica (Pedrinaci 2013). Además, permite promover la argumentación en el aula, que, coincidiendo con Sanmartí, Burgoa y Nuño (2011), es necesaria para el fomento del pensamiento crítico ante diferentes situaciones reales que afectan a nuestro patrimonio natural y geológico.

Como consideración final y propuesta de mejora, se recomienda al profesorado interesado en abordar este tema, complementar la secuencia diseñada con una salida de campo al lugar de interés. De esta manera, el alumnado podría contemplar in situ las formaciones geológicas del espacio natural, pudiendo incluso tomar fotografías de las mismas para emplear luego en las representaciones del proceso geológico. También sería oportuno, en el caso de disponer de un mayor número de sesiones, incluir una etapa de comunicación y justificación del modelo al resto de grupos; de modo que el alumnado pueda reflexionar acerca de sus representaciones y mejore con ello su capacidad comunicativa y argumentativa. 
Finalmente, indicar que la secuencia de tareas diseñada parece ser realmente motivadora para los estudiantes, ya que sirve para conectar los contenidos teóricos con el mundo real; de este modo, el alumnado puede encontrarle un sentido y utilidad y, al mismo tiempo, desarrolla competencias específicas del ámbito científico. Todo esto promueve el aprendizaje significativo. Sin embargo, son tareas exigentes y requieren, por parte de los/as docentes, de preparación didáctica, así como de una buena disposición y esfuerzo para su diseño, su implementación y su seguimiento.

\section{Agradecimientos}

Al proyecto ESPIGA, cofinanciado por la Agencia Estatal de Investigación y el Fondo Europeo de Desarrollo regional (FEDER), código PGC2018-096581-B-C22, en el que se enmarca este estudio. Las autoras agradecen la participación del alumnado participante.

\section{Referencias}

Acevedo-Díaz J. A., Vázquez Á., Martín M., Oliva J. M., Acevedo P., Paixão F., Manassero M. A. (2005). Naturaleza de la ciencia y educación científica para la participación ciudadana. Una revisión crítica. Revista Eureka sobre Enseñanza y Divulgación de las ciencias 2 (2), 121-140.

Ageitos N., Puig B. (2016). Modelizar la expresión de los genes para el aprendizaje de enfermedades genéticas en secundaria. Pesquisa e Ensaio, 18 (1), 65-84.

Bardin (1996). El análisis del contenido. Madrid: Akal.

Blanco P. (2015). Modelización y argumentación en actividades prácticas de geología en secundaria. Tese doctoral. Universidad de Santiago de Compostela, Santiago de Compostela.

Calonge A., Fermeli G., Meléndez G., Carvalho C. N., Rodrigues J. (2013). Geoschools, la importancia de las geo-rutas en la enseñanza de la geología. En J. Vegas, A. Salazar, E. Díaz-Martínez, C. Marchán (Eds.), Patrimonio geológico, un recurso para el desarrollo (pp. 495-504). Madrid: Cuadernos del Museo Geominero.

Carcavilla L. (2014). Guía práctica para entender el patrimonio geológico. Enseñanza de las Ciencias de la Tierra 22 (1), 5-18.

Evagorou M., Lymbouridou Chr., Nicolaou Chr. (2013). Using models with elementary school students as part of argumentation and decision making in a socio-scientific issue. Trabajo presentado en ESERA Conference, Nicosia, Chipre, del 2 al 9 de septiembre.

Friedrichsen P., Sadler T. D., Sadler, Graham, K., Brown P. (2016). Design of a socioscientific issue curriculum unit: Antibiotic resistance, natural selection, and modeling. International Journal of Designs for Learning 7(1), 1-18. DOI: https://doi.org/10.14434/ijdl.v7i1.19325

Fuertes-Gutiérrez I., Fernández-Martínez E (2014). Inventariar para conocer, conocer para valorar. Trabajando con el patrimonio geológico en el entorno de los centros educativos. Enseñanza de las Ciencias de la Tierra 22 (1), 38-48.

Fuertes-Gutiérrez I., Pérez M., González-Villanueva R., Arias F., Hernández R., De Miguel C.J., Escorihuela J., Cuevas-González J., García J. M. (2014). El valor didáctico del patrimonio geológico y el valor patrimonial de los recursos didácticos. Enseñanza de las Ciencias de la Tierra (22,1), 69-80. 
Jiménez-Aleixandre M. P. (2010). 10 ideas clave. Competencias en argumentación y uso de pruebas. Barcelona: Graó.

Lacreu H. (2001). La alfabetización geocientífica: ¿Avance corporativo o necesidad social? I Congreso Internacional de Educación. Actas en CD (Resumen Tomo I, pp. 262.). Córdoba, Argentina.

Lacreu H. (2007). La Historia del Paisaje como contenido esencial en la enseñanza obligatoria. Alambique 51, 76-87.

Marín Cepeda S. (2013) Una nueva geografía patrimonial; la diversidad, la psicología del patrimonio y la educación artística. Educación artística. Revista de Investigación (4), 217-224.

McNeill K. L., Krajcik J. (2008). Inquiry and scientific explanations: Helping students use evidence and reasoning. En J. Luft, R.L Bell, J. Gess-Newsome (Eds.). Science as inquiry in the secondary setting, 121-134.

Molinatti G., Girault, Hammond C. (2010). High School Students Debate the Use of Embryonic Stem Cells: The influence of context on decision making. International Journal of Science Education 32 (16), 2235-2251. 10.1080/09500691003622612f

Morón-Mongue H., Morón-Mongue Ma C. (2017). ¿Educación Patrimonial o Educacióm Ambiental?: perspectivas que convergen para la enseñanza de las ciencias. Revista Eureka sobre Enseñanza y Divulgación de las Ciencias 14 (1), 244-257.

DOI: http://dx.doi.org/10.25267/Rev_Eureka_ensen_divulg_cienc.2017.v14.11.18

Morón H., Wamba A. M. (2008). La importancia de la percepción de los riesgos ambientales en la formación inicial del profesorado. En H. Morón e A. M. Wamba (Eds.), XXIII Encuentros de Didáctica de las Ciencias Experimentales (pp. 1196-1209). Almería: Universidad de Almería.

Pedrinaci E. (2013). Alfabetización en Ciencias de la Tierra y competencia científica. Enseñanza de las Ciencias de la Tierra 21 (2), 208-214.

Puig B., Pérez Maceira J., Montero Vilar, S. (2015). La sucesión de terremotos del Delta del Ebro. Una secuencia para investigar las ideas del alumnado y la práctica de uso de pruebas. Praxis \& Saber, 6. doi: https://doi.org/10.19053/22160159.3574

Sadler T. (2011). Socioscientific issues in the classroom. Dordrecht: Springer.

Sanmartí N., Burgoa B., Nuño T. (2011). ¿Por qué el alumnado tiene dificultad para utilizar sus conocimientos científicos escolares en situaciones cotidianas? Alambique 67, 62-69.

Simonneaux L., Simonneaux J. (2009). 'Students' socio-scientific reasoning concontroversies from the viewpoint of Education for Sustainable Development. Cultural Studies in Science Education (4), 657-687.

Vidal J. R., Cotelo T. (2017). Estudio de las posibles consecuencias del ascenso del nivel del mar en los procesos erosivos de los acantilados en el monumento natural de la playa de “As Catedrais". Un estudio do Instituto Universitario de Xeoloxía: Isidro Parga Pondal e a Universidade da Coruña. Galicia: Xunta de Galicia.

Zeidler D. L., Berkowitz M., Bennett K. (2013). Thinking (scientifically) responsibly: The cultivation of character in a global science education community. En M.P. Mueller, D.J. Tippins, A.J. Steward (Eds.), Assessing schools for generation R (Responsibility): A guide to legislation and school policy in science education (pp. 83-99). Netherlands: Springer. 
Anexo 1: Modelo científico escolar de referencia

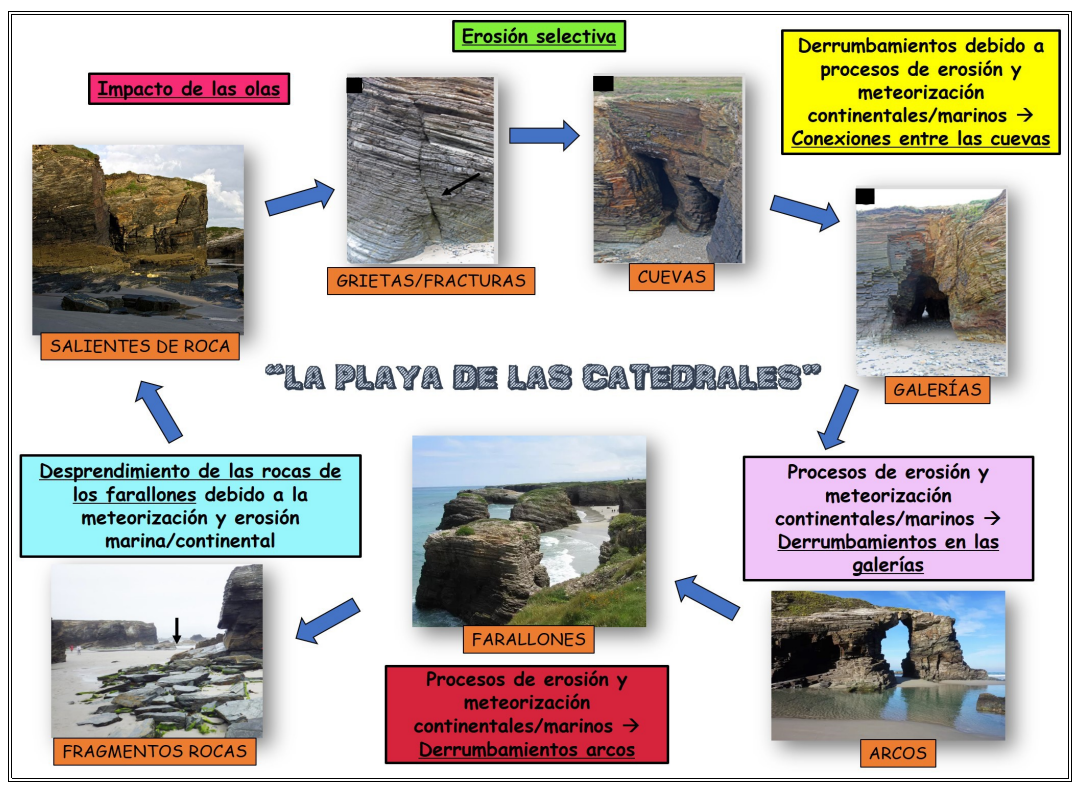

Figura 14. Modelo científico escolar de referencia. Fuentes de las imágenes e información: http:/ / ascatedrais.gal/ascatedrais/; Vidal y Cotelo 2017. Elaboración de la propia autora. 